\title{
Trends in growth and mortality of three coral species (Anthozoa: Scleractinia), including effects of transplantation
}

\author{
Helen T. Yap, Porfirio M. Aliño, Edgardo D. Gomez
}

Marine Science Institute, University of the Philippines, Diliman, Quezon City, Philippines

\begin{abstract}
Three ecologically dominant coral species in a northern Philippine reef were compared in terms of growth and mortality, and responses to transplantation. The purpose of this study was to examine the feasibility of using the species concerned in establishing new coral populations through deliberate fragmentation. The species, Acropora hyacinthus, Pocillopora damicornis and Pavona frondifera, displayed distinct differences which could be related to their respective life-history strategies. $A$. hyacinthus showed tendencies towards an $r$-mode, with rapid linear growth but also high mortality rates. Response to transplantation was poor Pocillopora damicornis had intermediate linear growth rates and relatively high mortality. Transplants fared poorly in the initial part of the experiment, though they showed successful adaptation after a year. Mortality rates of both $A$. hyacinthus and $P$. damicornis were increased by high temperatures during certain times of the year. Pavona frondifera had the highest linear growth rates and no mortality, tending towards a $K$-mode of life history strategy. It showed the best response to transplantation. This species is thus a suitable candidate for large-scale reef restoration.
\end{abstract}

\section{INTRODUCTION}

More and more interest has been generated recently in the concept of ecosystem rehabilitation or restoration ecology (Jordan et al. 1987, Ravera 1989). One novel application of this approach is in the use of coral transplantation to help replenish damaged reef areas (Harriott \& Fisk 1988, Yap et al. 1990). This involves ecological stimulation, or the ability of adult coral colonies introduced into a damaged reef area to establish themselves, grow normally, and develop into normally functioning populations.

In the present work, measurements were made of rates of occupation of available space based on projected surface area. Studies on areal increments of reef corals, from the point of view of reef occupancy, are reviewed in Buddemeier \& Kinzie (1976).

This investigation had the following objectives: (1) to compare the growth and mortality of different coral species; (2) to relate growth and mortality with environmental factors, particularly day length and temperature; (3) to study the effects of manipulations associated with transplantation on growth and mortality by com- parisons of undisturbed colonies (the controls) and transplants.

Thus, an important aspect of this study was the use of coral transplantation to gain insights on coral growth and survival strategies. As demonstrated in a tropical species, Acropora pulchra, colony breakage and reattachment to a new substrate cause stress and induce a period of trauma, reflected in reduced growth and/or increased mortality (Yap \& Gomez 1985). If acclimation is successful, a transplanted coral would begin to grow and respond similarly to a naturally growing colony. The level and duration of trauma and the nature of acclimation may be inferred from comparisons of controls and transplants.

In addition coral growth, often coupled with transplantation, is a useful tool in the study of the organism's responses to environmental change (reviewed in Maragos 1974, Buddemeier \& Kinzie 1976, Yap 1981). Growth, together with survival, also reflects the ability of a species to acquire or compete for essential space on the reef after the reproductive and recruitment phase.

For purposes of this study, 3 coral species were chosen on the basis of their importance (i.e. ecological 
dominance) in certain Philippine reefs: Acropora hyacinthus, Pavona frondifera, and Pocillopora damicornis

\section{MATERIALS AND METHODS}

Study site. The study site is a backreef environment on the eastern side of Cangaluyan Island, Pangasinan, Philippines, at $16^{\circ} 22^{\prime} \mathrm{N}$ and $120^{\circ} 00^{\prime} \mathrm{E}$ (Fig. 1). Some areas harboring many colonies of Montipora ramosa and Acropora hyacinthus are exposed at low tide. In

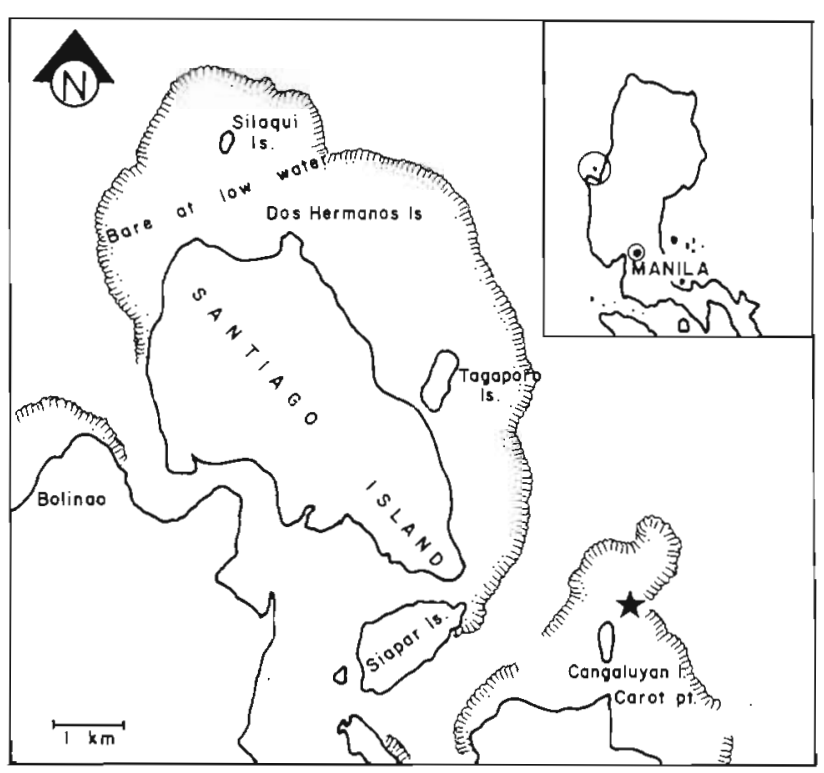

Fig. 1. Location of the coral transplant study site ( $\star$ ) at Cangaluyan Island, Pangasinan, Philippines

the slightly deeper ( 1 to $3 \mathrm{~m}$ ) portions aggregates of $A$. bruggemanni, Pavona frondifera and Pocillopora damicornis are also found. Scattered sandy patches abound with coral rubble and thickets of $A$. pulchra and A. formosa. Massive Porites heads are also common, together with some faviids settled mostly on compacted hard substrate. Conspicuous associated organisms are macroalgae like Padina, Laurencia and Acanthophora, and sea grasses. Isis and Callyspongia are the dominant associated sessile invertebrate fauna while Diadema and holothurians are the more visible motile invertebrates.

Transplantation. In April 1983, 2 adjacent limestone rocks averaging $1 \mathrm{~m}$ high were cleared of all rubble and encrusting organisms. Portions of Pocillopora damicornis with an average projected area of $74 \mathrm{~cm}^{2}$ were broken off at random from colonies in a patch a few meters from the transplant site and at approximately the same depth. Pieces of Acropora hyacinthus with an average projected area of $115 \mathrm{~cm}^{2}$ were also broken off at random from colonies in a nearby patch. Pavona frondifera transplants with an average projected area of $89 \mathrm{~cm}^{2}$ were broken off parent colonies right next to the transplant site. In the case of the last species, the portions broken off were small extensions on the substrate of the large colonies, making breakage easier.

The source patches and transplant site were located in close proximity to eliminate the site effect in transplantation. Effects of relocation were shown to be absent, anyway, in another tropical species, Acropora pulchra (Yap \& Gomez 1985).

The fragments or portions to be transplanted were loosely piled in a plastic basket and carried underwater by 2 divers. Those of the same species were grouped together and spaced approximately $16 \mathrm{~cm}$ apart on the cleared rock surfaces and attached with underwater epoxy. No toxic reactions were expected from this treatment (Birkeland 1976). Sample sizes (n) were a little over 30 each.

Controls. Undisturbed colonies growing in proximity to each other in the source patches of each species were designated as the controls: ca 10 for Acropora hyacinthus, 20 for Pavona frondifera and 30 for Pocillopora damicornis. These numbers were dictated by the availability of remaining healthy colonies in each patch as well as by colony area. Average initial sizes (expressed in terms of projected area) for the controls were as follows: $1000 \mathrm{~cm}^{2}$ for A. hyacinthus, $380 \mathrm{~cm}^{2}$ for Pavona frondifera, and $320 \mathrm{~cm}^{2}$ for Pocillopora damicornis.

Measurement. Controls and transplants were marked by tying plastic number tags around their bases or some convenient part of the corallum. A steel caliper calibrated in millimeters was used to obtain the following dimensions: length ( $L=$ the perceived longest dimension of the corallum through the center) and width ( $W=$ the perceived longest dimension perpendicular to the length). Only live portions were measured, since these were the actual growing areas.

The measurements were translated into a projected circular area by means of the formula (after Anonymous 1984):

$$
A=\pi\left[\frac{\sqrt{L \times W}}{2}\right]^{2}
$$

Measurements were made at average intervals of $5 \mathrm{wk}$, starting in April 1983 for the transplants and June 1983 for the controls, and lasting until November 1984. After this, measurements were again made in October 1987 and May 1988. It will be noted that there was a difference in initial size between controls and transplants. It was assumed that this would not affect comparisons, because the size effect on colony increments 
(Buddemeier \& Kinzie 1976) is believed not to be manifested in colonies greater than $25 \mathrm{~cm}^{2}$ (Connell 1973). Nevertheless, actual measured areal increments were converted to percentage increments (based on area measured the preceding month) in order to standardize growth data and provide a better basis for comparison (Buddemeier \& Kinzie 1976, Richard Grigg pers. comm.).

During each monthly visit, all colonies which had lost at least $50 \%$ of their living tissue were considered dead and were replaced, as these usually did not survive until the next monitoring visit. Mortality rate for each control and transplant group was considered to be the percentage of dead individuals over the total number in that group per measurement interval. The frequency of replacement of dead transplants corresponded to mortality rates as reported, since an effort was made to retain the original sample sizes. In one species, Pocillopora damicornis, replacement was discontinued after 1 yr because of a significant drop in mortality.

Environmental parameters. For each measurement interval, the following environmental factors were determined: average day length, maximum temperature and minimum temperature. Mean day length was computed from records in daily weather reports. Maximum and minimum temperatures were obtained using a Taylor maximum-minimum recording thermometer permanently set at the bottom at the transplant site. Since the area was shallow and well mixed, it was presumed that the readings were true for the general reef area.

In addition, visual/subjective observations were made of possible significant biological interactions such as predation and competition.

Statistical analysis. Differences in percentage growth and mortality rates among the 3 species were examined using the Kruskal-Wallis test (Zar 1984). Controls and transplants were analyzed separately. Where significant differences were established, nonparametric Tukey-type multiple comparisons tests were employed to determine which groups differed. Differences between controls and transplants of each species were evaluated using the Mann-Whitney test with tied ranks. With respect to the above analyses, it should be noted that data for different times within a treatment were not independent of each other since for the most part they pertained to the same batch of corals, except in cases where transplants were continually replaced.

Correlations (Pearson's product-moment correlation coefficient; Sokal \& Rohlf 1981) were run between day length, maximum temperature and minimum temperature and each of the following parameters: absolute growth rates of controls and transplants, and percentage mortalities of controls and transplants.

\section{RESULTS}

\section{Environmental factors}

As was expected, both day length and temperature displayed similar trends (Fig. 2). The highest recorded value of mean day length was $12.97 \mathrm{~h}$ for the interval June to July 1983; of maximum temperature, $33^{\circ} \mathrm{C}$ for the months of July to October 1983; and of minimum temperature, $31^{\circ} \mathrm{C}$ for the period April to June 1984 . The lowest values for mean day length and minimum temperature, $11.22 \mathrm{~h}$ and $24^{\circ} \mathrm{C}$ respectively, occurred in the interval December 1983 to January 1984. Lowest maximum temperature, $29^{\circ} \mathrm{C}$, was registered during the interval January to February 1984

\section{Growth}

Differences among species

Absolute areal increments of controls and transplants are shown in Tables $1 \& 2$ respectively. Observations on undisturbed (control) colonies showed Acropora hyacinthus to have the highest growth rates. Values ranged from 6.9 to $117 \mathrm{~cm}^{2} \mathrm{mo}^{-1}$. Growth rates of Pavona frondifera were from -11.8 to $46.8 \mathrm{~cm}^{2} \mathrm{mo}^{-1}$.
Fig. 2. Day length $(\bullet \bullet)$, maximum temperature $(0-0)$ and minimum temperature $(\Delta-\Delta)$ over an annual cycle from April 1983 to May 1984 at the study site

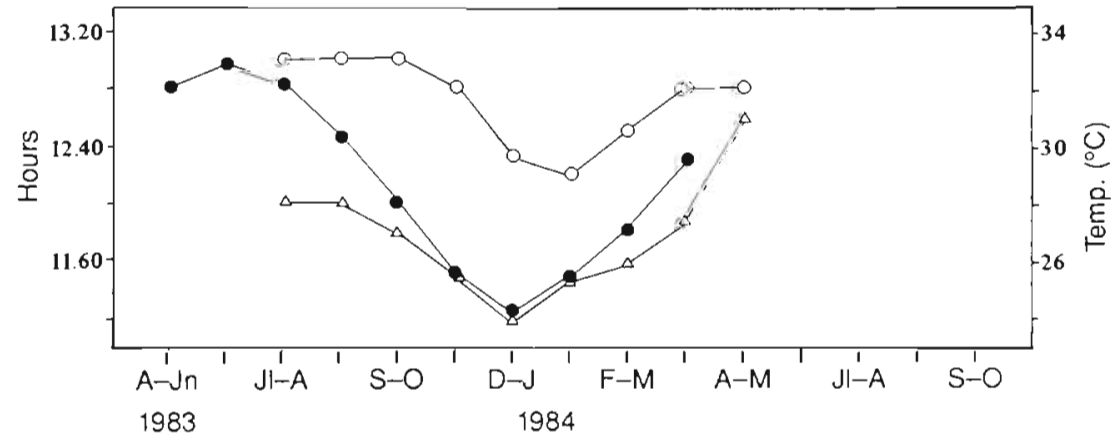


Table 1. Acropora hyacinthus, Pavona frondifera, Pocillopora damicornis. Actual mean areal increments of $\mathrm{controls}\left(\mathrm{cm}^{2} \mathrm{mo} \mathrm{o}^{-1}\right.$; means $\pm S D$ ). No. of samples in parentheses

\begin{tabular}{|c|c|c|c|c|c|c|}
\hline \multirow{2}{*}{$\begin{array}{l}\text { Interval } \\
\text { Jun-Jul } 1983\end{array}$} & \multicolumn{2}{|c|}{ A. hyacinthus } & \multicolumn{2}{|c|}{ P. frondifera } & \multicolumn{2}{|c|}{ P. damicornis } \\
\hline & $50.6 \pm 45.5$ & (7) & $26.8 \pm$ & (9) & $-3.5 \pm 62.8$ & $(27)$ \\
\hline Jul-Aug 1983 & $8.1 \pm 59.4$ & (9) & $14.5 \pm$ & (9) & $-44.9 \pm 71.3$ & (21) \\
\hline Aug̣ Sep 1983 & $46.4 \pm 60.5$ & (4) & $17.9 \pm$ & (19) & $-5.2 \pm 41.2$ & (18) \\
\hline Sep-Oct 1983 & $51.3 \pm 76.8$ & (7) & $14.8 \pm$ & (19) & $-5.8 \pm 38.8$ & $(21)$ \\
\hline Oct-Dec 1983 & $37.7 \pm 38.9$ & (4) & $13.7 \pm$ & (18) & $3.3 \pm 25.0$ & (19) \\
\hline Dec 1983-Jan 1984 & $16.0 \pm 63.7$ & (5) & $5.9 \pm$ & (18) & $5.6 \pm 32.6$ & (19) \\
\hline Jan-Feb 1984 & $6.9 \pm 115.2$ & (11) & $29.4 \pm$ & (15) & $-2.9 \pm 48.6$ & (19) \\
\hline Feb-Mar 1984 & $17.8 \pm 56.1$ & (9) & $-11.8 \pm$ & $(17)$ & $-1.2 \pm 49.4$ & (22) \\
\hline Mar-Apr 1984 & $59.2 \pm 137.6$ & (11) & $26.9 \pm$ & $(22)$ & $10.9 \pm 20.2$ & (20) \\
\hline Apr-May 1984 & $51.0 \pm 119.0$ & (11) & $17.6 \pm 44.6$ & $(22)$ & $8.7 \pm 41.7$ & (21) \\
\hline May-Jul 1984 & $117.0 \pm 225.1$ & (11) & $23.2 \pm 111.2$ & $(22)$ & $2.2 \pm 44.0$ & (19) \\
\hline Jul-Aug 1984 & $64.1 \pm 102.8$ & (14) & $46.8 \pm 48.5$ & (20) & $-3.3 \pm 36.9$ & $(20)$ \\
\hline Aug-Sep 1984 & $71.1 \pm 162.0$ & (14) & $13.4 \pm 36.3$ & (20) & $16.8 \pm 31.0$ & (19) \\
\hline Sep-Oct 1984 & $88.9 \pm 89.0$ & (14) & $19.7 \pm 25.6$ & (21) & $11.1 \pm 30.7$ & (19) \\
\hline Oct-Nov 1984 & $12.2 \pm 164.3$ & (13) & $12.0 \pm 41.4$ & (21) & $-14.4 \pm 42.9$ & $(17)$ \\
\hline Nov 1984-Feb 1985 & No data & & No data & & $12.5 \pm 13.7$ & (15) \\
\hline
\end{tabular}

Table 2. Acropora hyacinthus, Pavona frondifera, Pocillopora damicornis. Actual mean areal increments of transplants $\left(\mathrm{cm}^{2} \mathrm{mo}^{-1}\right.$; means $\pm \mathrm{SD})$. No. of samples in parentheses

\begin{tabular}{|c|c|c|c|c|c|c|}
\hline \multirow{2}{*}{$\begin{array}{l}\text { Interval } \\
\text { Apr-Jun } 1983\end{array}$} & \multicolumn{2}{|l|}{ A. hyacinthus } & \multicolumn{2}{|c|}{ P. frondifera } & \multicolumn{2}{|c|}{ P. damicornis } \\
\hline & $-5.5 \pm 12.4$ & $(7)$ & $10.3 \pm$ & (8) & $2.9 \pm 4.8$ & (11) \\
\hline Jun-Jul 1983 & (All dead) & & $5.7 \pm$ & $(29)$ & $1.5 \pm 4.4$ & (18) \\
\hline Jul-Aug 1983 & $50.2 \pm 115.0$ & (2) & $7.0 \pm$ & (29) & $0.1 \pm 5.0$ & (16) \\
\hline Aug-Sep 1983 & $-1.5 \pm 25.9$ & (18) & $13.3 \pm 14.1$ & (30) & $2.9 \pm 5.4$ & (20) \\
\hline Sep-Oct 1983 & $-18.6 \pm 34.2$ & (17) & $9.0 \pm$ & (31) & $0.7 \pm 13.5$ & (25) \\
\hline Oct-Dec 1983 & $-2.0 \pm$ & (19) & $10.1 \pm$ & (27) & $5.6 \pm 9.0$ & (29) \\
\hline Dec 1983-Jan 1984 & $-4.1 \pm 13.6$ & (21) & $5.8 \pm 1.3 .9$ & $(22)$ & $3.7 \pm 12.6$ & (28) \\
\hline Jan-Feb 1984 & $-6.0 \pm 26.2$ & (22) & $8.1 \pm$ & (25) & $4.9 \pm 7.1$ & (26) \\
\hline Feb-Mar 1984 & $-0.5 \pm$ & (18) & $5.9 \pm$ & (26) & $9.8 \pm 8.1$ & (26) \\
\hline Mar-Apr 1984 & $-5.4 \pm 13.5$ & (18) & $13.4 \pm$ & (28) & $8.3 \pm 12.7$ & (28) \\
\hline A.pr-May 1984 & $-2.2 \pm 12.2$ & (17) & $21.8 \pm$ & (29) & $11.2 \pm 12.2$ & (29) \\
\hline May-Jul 1984 & $-10.0 \pm 19.1$ & (6) & $18.8 \pm 37.1$ & (28) & $10.0 \pm 10.9$ & (28) \\
\hline Jul-Aug 1984 & 14.8 & (1) & $11.5 \pm 10.9$ & (28) & $6.5 \pm 14.9$ & (28) \\
\hline Aug-Sep 1984 & 23.5 & (1) & $39.7 \pm 107.9$ & (24) & $4.0 \pm 8.7$ & (29) \\
\hline Sep-Oct 1984 & 26.0 & (1) & $27.2 \pm 33.3$ & (23) & $13.2 \pm 18.4$ & (29) \\
\hline Oct-Nov 1984 & 31.9 & (1) & $8.2 \pm 9.5$ & (24) & $11.2 \pm 11.3$ & (28) \\
\hline Nov $1984-$ Oct 1987 & & & $15.8 \pm 5.9$ & (15) & $11.8 \pm 6.0$ & (18) \\
\hline Oct 1987-May 1988 & & & $11.9=14.6$ & (20) & $22.9 \pm 30.1$ & (14) \\
\hline
\end{tabular}

Natural colonies of Pocillopora damicornis had the lowest growth rates, varying from -44.9 to $16.8 \mathrm{~cm}^{2} \mathrm{mo}^{-1}$

Negative growth rates in this context denote the loss of living tissue due to death of portions of a colony or breakage due to undetermined reasons. It by no means indicates death of the entire colony, because the colony could recover from tissue loss (up to a certain extent) and continue to grow normally. This concept of shrinkage and expansion of living tissue is important in the context of occupancy of the reef by living coral cover.

Transplants revealed different patterns (Table 2). pavona frondifera showed the highest, and apparently also most stable, growth rates, ranging from 5.7 to $39.7 \mathrm{~cm}^{2} \mathrm{mo}^{-1}$. Growth rates of Pocillopora damicornis, from 0.1 to $22.9 \mathrm{~cm}^{2} \mathrm{mo}^{-1}$, were lower initially, although after November 1983 ( 7 mo after transplantation) they appeared to have caught up with those of Pavona frondifera. Acropora hyacinthus consistently exhibited the lowest growth rates (Table 2), denoting continual loss of living tissue.

Similar trends were apparent when the data were standardized by expressing growth as \% increase over the previous colony area (Fig. 3). There were no significant differences between controls of Acropora hyacin- 

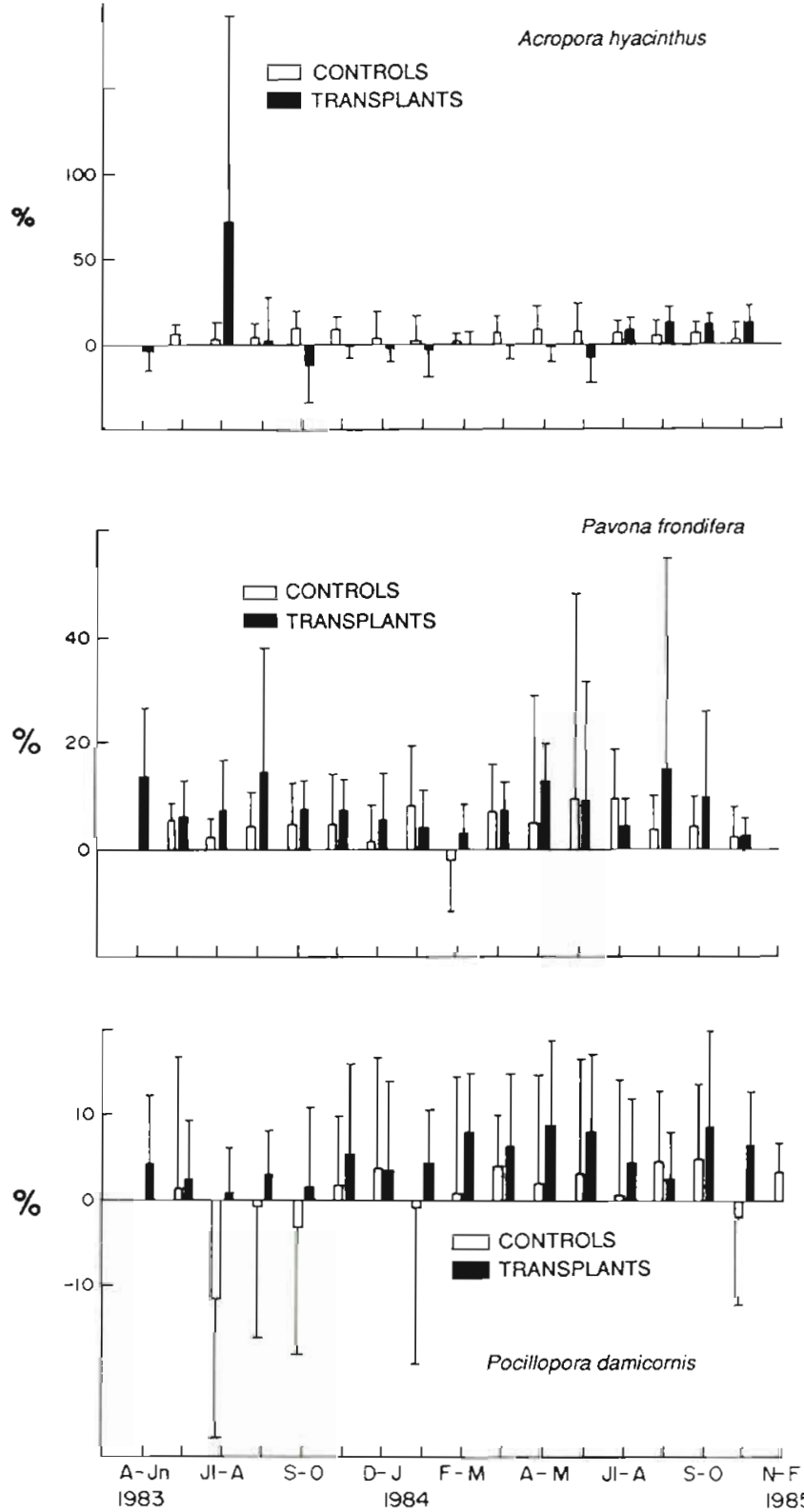

Fig. 3. Acropora hyacinthus, Pavona frondifera, Pocillopora damicornis. Percentage growth rates (based on previous colony area) of controls and transplants (June 1983 to November 1984 for controls, April 1983 to November 1984 for transplants). Note that vertical scales differ

thus and Pavona frondifera, and both showed significantly higher growth rates than Pocillopora damicornis (Table 3). Among the transplants, percentage growth rates of Pavona frondifera and Pocillopora damicornis were not significantly different. Both were significantly greater than that of $A$. hyacinthus (Table 3 ).

Growth rates through time showed no discernible seasonal trends.
Results of transplantation

Making use of the standardized growth data (Fig. 3) it could be seen that in 2 species, Pavona frondifera and Pocillopora damicornis, percentage growth rates of transplants exceeded those of the controls (Table 4).

About a year after transplantation, absolute growth rates of transplants of Pavona frondifera and Pocillopora damicornis began to approximate those of the controls (Table $1 \& 2$ ). Since Pavona frondifera transplants experienced no mortality, their growth rates reflect those of well-established specimens of the same 'age'. Replacement of $P$. damicornis transplants due to mortality was done until April 1984 so that growth rates before this date are those of specimens of varying 'age', as was the case for Acropora hyacinthus during the whole experimental period. Growth rates of $P$. damicornis after May 1984 are those of well-established transplants which were no longer replaced.

Examination of the data shows that absolute areal increments of Pavona frondifera transplants $5 \mathrm{yr}$ after establishment were within the same range as the initial rates. Absolute increments of Pocillopora damicornis transplants attained stable levels about a year after transplantation.

\section{Mortality}

\section{Differences among species}

Percentage mortality of controls and transplants of Acropora hyacinthus and Pocillopora damicornis is presented in Fig. 4. Mortality was not observed in controls or transplants of Pavona frondifera. From June to September 1983, controls of $A$. hyacinthus experienced higher mortality than Pocillopora damicornis (Fig. 4). After January 1984, no more mortality occurred for controls of all species, except for A. hyacinthus in November 1984. Statistical tests detected no overall significant differences.

Among the transplants, mortality rates of Acropora hyacinthus and Pocillopora damicornis did not differ significantly (Table 3 ).

With respect to temporal trends, controls and transplants of Pocillopora damicornis and transplants of Acropora hyacinthus showed a peak in mortality around July 1983 (Fig. 4)

\section{Results of transplantation}

Transplants of Acropora hyacinthus and Pocillopora damicornis had significantly higher mortality rates than the controls (Table 4). 
Table 3. Comparisons of percentage growth and mortality rates among Acropora hyacinthus (1), Pavona frondifera (2) and Pocillopora damicornis (3) using non-parametric Tukey-type multiple comparisons tests $(\mathrm{p}<0.05)$ after the Kruskal-Wallis test showed significant differences

\begin{tabular}{|c|c|c|c|c|c|}
\hline Comparison & Difference & $S E$ & $q$ & $\mathrm{q}_{0.05,3}$ & Conclusion \\
\hline \multicolumn{6}{|c|}{ Percentage growth } \\
\hline \multicolumn{6}{|l|}{ Controls } \\
\hline 2 vs 1 & 0.40 & 4.90 & 0.082 & 2.394 & $\begin{array}{c}\text { Accept } H_{0} \\
\left(\mu_{2}=\mu_{1}\right)\end{array}$ \\
\hline 1 vs 3 & 15.23 & 4.82 & 3.160 & 2.394 & $\begin{array}{l}\text { Reject } H_{0} \\
\left(\mu_{1} \neq \mu_{3}\right)\end{array}$ \\
\hline 2 vs 3 & 15.63 & 4.82 & 3.243 & 2.394 & $\begin{array}{l}\text { Reject } H_{0} \\
\left(\mu_{2} \neq \mu_{3}\right)\end{array}$ \\
\hline \multicolumn{6}{|l|}{ Transplants } \\
\hline 2 vs 1 & 14.22 & 4.93 & 2.884 & 2.394 & $\begin{array}{l}\text { Reject } H_{0} \\
\left(\mu_{2} \neq \mu_{1}\right)\end{array}$ \\
\hline 3 vs 1 & 5.16 & 4.93 & 1.249 & 2.394 & $\begin{array}{l}\text { Reject } H_{0} \\
\left(\mu_{3} \neq \mu_{1}\right\}\end{array}$ \\
\hline 2 vs 3 & 9.06 & 4.85 & 1.868 & 2.394 & $\begin{array}{l}\text { Accept } H_{0} \\
\left(\mu_{2}=\mu_{3}\right)\end{array}$ \\
\hline \multicolumn{6}{|c|}{ Percentage mortality } \\
\hline \multicolumn{6}{|c|}{ Transplants (mortality rates of controls not significantly different) } \\
\hline 1 vs 2 & 22.78 & 4.95 & 4.602 & 2.394 & $\begin{array}{c}\text { Reject } H_{0} \\
\left(\mu_{1} \neq \mu_{2}\right)\end{array}$ \\
\hline 1 vs 3 & 9.56 & 4.95 & 1.931 & 2.394 & $\begin{array}{c}\text { Accept } H_{0} \\
\left(\mu_{1}=\mu_{3}\right)\end{array}$ \\
\hline 3 vs 2 & 13.22 & 4.95 & 2.671 & 2.394 & $\begin{array}{l}\text { Reject } H_{0} \\
\left(\mu_{3} \neq \mu_{2}\right)\end{array}$ \\
\hline
\end{tabular}

Table 4. Acropora hyacinthus, Pavona frondifera, Pocillopora damicornis. Comparisons of percentage growth and mortality rates between controls (C) and transplants $(T)$ : results of Mann-Whitney test with tied ranks $(\mathrm{p}<0.05)$

\begin{tabular}{|c|c|c|c|c|}
\hline Species & Conclusion & $U^{\prime}$ & $U_{0.05(1)}$ & Result \\
\hline \multicolumn{5}{|c|}{ Percentage growth } \\
\hline A. hyacinthus & $\mathrm{C}=\mathrm{T}$ & 151 & 153 & $U^{\prime}<U_{0.05(1), 15,15}$ \\
\hline p. frondifera & $\mathrm{T}>\mathrm{C}$ & 179.5 & 163 & $U^{\prime}>U_{0.05(1) .15,16}$ \\
\hline P. damicornis & $T>C$ & 210 & 173 & $U^{\prime}>U_{0.05(1), 16,16}$ \\
\hline \multicolumn{5}{|c|}{ Percentage mortality } \\
\hline A. hyacinthus & $\mathrm{T}>\mathrm{C}$ & 206.5 & 163 & $U^{\prime}>U_{005(1), 15.15}$ \\
\hline P. damicornis & $T>C$ & 180 & 173 & $U^{\prime}>U_{0} 05(1) .16 .16$ \\
\hline
\end{tabular}

\section{Correlations of growth and mortality with day length and temperature}

The parameters day length and temperature were singled out for analysis because they best characterize the changes in seasons to which the organisms respond. Correlations between growth and these environmental factors were inconclusive (Table 5)

Correlations between mortality and day length were indicative of possible trends, being positive and highly significant $(p<0.05)$ for both controls and transplants of Acropora hyacinthus and Pocillopora damicornis (it is to be recalled that Pavona frondifera experienced no mortality).
Correlations between mortality and temperature were consistently positive. Maximum temperature correlated significantly $(\mathrm{p}<0.10)$ with mortality of controls and transplants of Pocillopora damicornis.

\section{DISCUSSION}

\section{Differences among species}

Growth

Of the 3 species studied, the table acroporid, Acropora hyacinthus, exhibited the highest absolute growth 

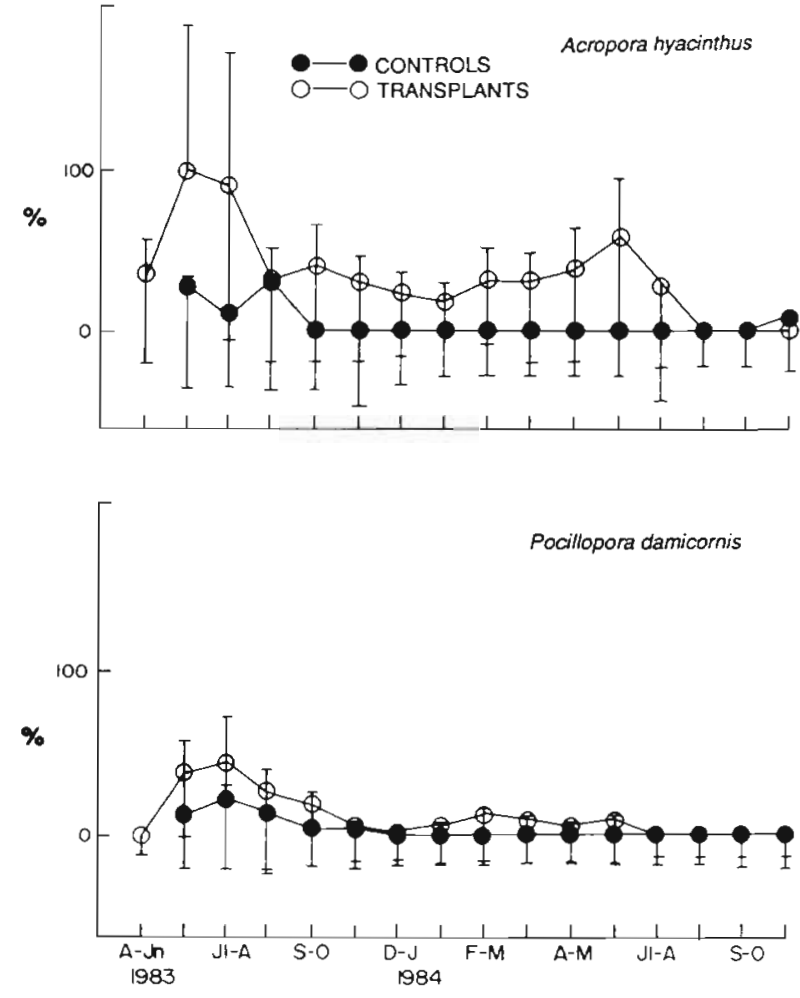

Fig. 4. Acropora hyacinthus, Pocillopora damicornis. Percentage mortality rates of controls and transplants (June 1983 to November 1984 for controls, April 1983 to November 1984 for transplants). No mortality was observed in Pavona frondifera rates in natural settings. This is in accordance with what is known about this species (Mayor 1924), which has a more planar habit, and the general observation that the genus Acropora is among the fastest growing corals (reviewed in Buddemeier \& Kinzie 1976, Yap 1981).

Growth rates of natural Pavona frondifera colonies were also relatively high, and while growth of Acropora hyacinthus fluctuated greatly, that of the former was relatively steady. $P$. frondifera, too, had the highest absolute growth rates among the transplants. It thus appears to be a more successful component of the reef community. Both $P$. frondifera and $A$. hyacinthus were dominant in the reef flat (Aliño 1985).

The negative growth rates (i.e. loss of living tissue) of the control Pocillopora damicornis colonies may indicate that natural populations were diminishing. It was not as conspicuous or abundant as the other 2 species. Moreover, patches situated about the general area were observed to contain many dead or dying colonies.

Adequate data for purposes of comparison are available for various species of Acropora and Pocillopora in the Philippines, as reported in a review by Gomez et al. (1985). The genus Acropora was also shown to have the highest linear growth rates. There was a wide range in values, though not different from those in the present study. Several species of the genus Pocillopora also registered growth within the range of the positive values reported here for $P$. damicornis (i.e. 1.2 to $8.4 \mathrm{~cm}^{2}$

Table 5. Acropora hyacinthus, Pavona frondifera, Pocillopora damicornis. Controls and transplants: correlations of actual growth and mortality with day length, maximum temperature, and minimum temperature

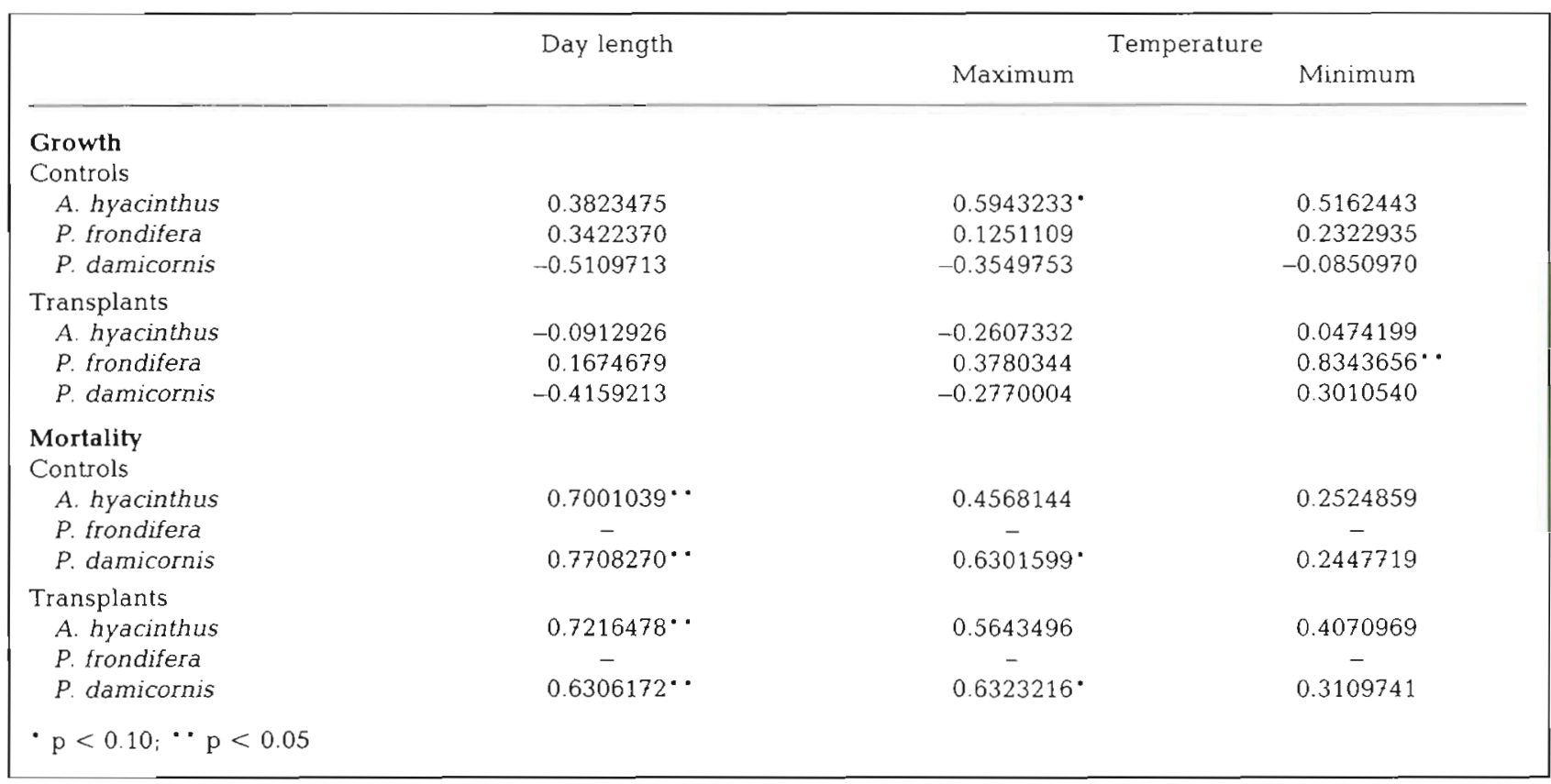


$\mathrm{mo}^{-1}$ for different species). In both the Acropora and Pocillopora species, the ranges of values for natural colonies and transplants overlapped.

\section{Mortality}

Although Acropora hyacinthus was the fastest grower, it also had relatively high mortality rates in both the control and transplant groups. This observation, coupled with the fast, but irregular, growth, may be indicative of an $r$-strategy for this species. Its widespread occurrence and relatively large cover on the reef are a sign of rapid proliferation and high recruitment rates (see discussion below on reproductive strategy). However, observations of many dead and dying colonies also indicate high turnover, with dead colonies or parts of colonies providing a substrate for new colonies of the same or other species.

Mortality rates of Pocillopora damicornis were apparently lower than those of Acropora hyacinthus, although statistical tests showed these not to be significantly different for both controls and transplants. This finding shows that $P$. damicornis is also a relatively sensitive species. This was borne out by observations of many dead and dying colonies in the study area. The species thus appears to easily succumb to stress. Whether this stress is internal (i.e. a physiological problem such as a disease) or external (i.e. from the environment) has not been established.

Mortality was not observed in either controls or transplants of Pavona frondifera, demonstrating this to be a hardy species. Its good survival rate and relatively rapid growth could account for its relative success and dominance on the reef.

\section{Results of transplantation}

Of the 3 species, Acropora hyacinthus was the least amenable to transplantation by the methods used. Survival was poor, and growth was consistently negative so that it had the lowest rates of all the species. Most transplants steadily deteriorated soon after attachment to their new substrate.

The reaction to transplantation may be due in part to the growth form of this species, where breakage results in a relatively large damaged area as compared to the other 2 species. The transplanted portion would then have to expend relatively more energy in repairing the damage (by tissue regeneration, etc.). If the energetic cost of repair is too high, we speculate that the coral would readily succumb to additional physiological or environmental stresses.

During the first year of the experiment, Pocillopora damicornis transplants continually experienced mortality and with each monthly visit a fraction of these had to be replaced. After the first year of transplantation, mortality no longer occurred. This is suggestive of an initial period characterized by adverse reactions to the stresses associated with transplantation, after which the transplants become well established. This may be related to prevailing temperatures at the time (see discussion below on possible seasonal effects).

Pavona frondifera transplants were observed to grow well (Fig. 5), and to approximate growth of the controls throughout the experimental period. This is a confirmation of the superiority of the species in terms of growth and survival strategies under the prevailing environmental conditions.

Percentage growth rates of transplants of Pavona frondifera and Pocillopora damicornis did not differ significantly and were higher than those of the respective controls for both species. The observed higher percentage growth of transplants as compared to the controls may be a manifestation of a size effect. For many species, there is a general impression that smaller colonies grow faster (i.e. calcify more rapidly) than larger ones (Buddemeier \& Kinzie 1976),

On the other hand, Kinzie \& Sarmiento (1986) determined that absolute growth in Pocillopora damicornis is independent of size. If this is the case, then this should also result in higher percentage growth for the transplants as compared to the controls.

In contrast to the trends in growth, transplants of Acropora hyacinthus and Pocillopora damicornis experienced higher mortality than the controls. This is most likely explained by the stress caused by transplantation, as discussed above, as well as the greater susceptibility of smaller colonies to attack by sessile competitors such as algae and sponges, or by predators such as gastropods. In a study on the Great Barrier Reef, Harriott (1985) similarly observed higher mortality in smaller colonies, possibly due to lower resistance to stresses associated with bleaching.

\section{Implications of reproductive strategy for transplantation effects}

The responses to fragmentation for purposes of transplantation may be related to the reproductive strategy' a species has evolved. Acropora hyacinthus, for example, has been shown to release gametes into the water column (Harrison et al. 1984, Aliño pers. obs.). Given this reproductive mode, it may not have developed a mechanism for reproducing by fragmentation, so that high mortalities are experienced by transplants.

On the other hand, it is probable that the most successful transplant species in this study, Pavona frondi- 

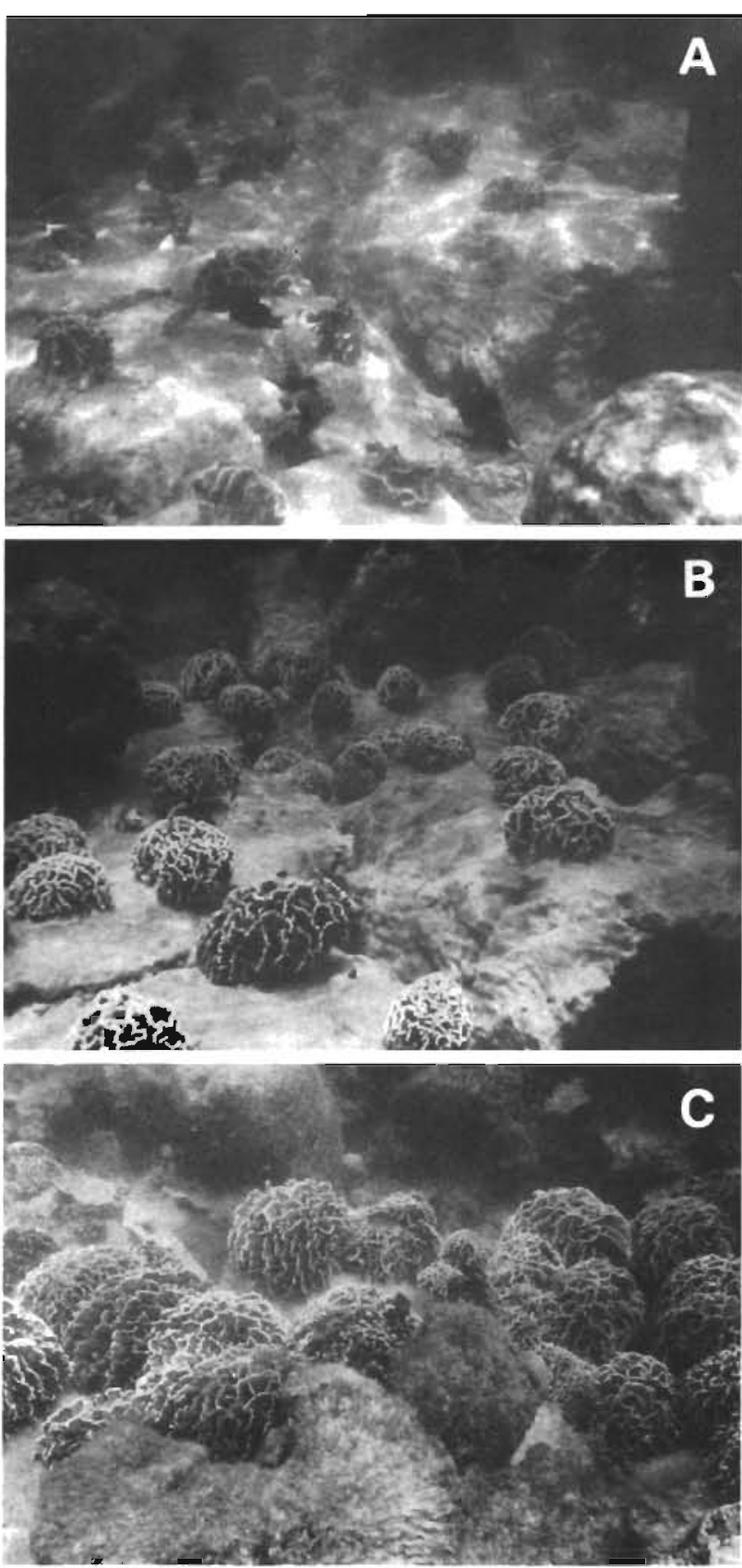

Fig. 5. Pavona frondifera. Growth of transplants: (A) April 1983; (B) April 1984; (C) May 1988

fera, includes fragmentation in its repertoire of reproductive strategies. Asexual reproduction is known to be important in a related species, $P$. cactus (Willis \& Ayre 1985).

Pocillopora damicornis is known to reproduce mainly by planulation, at least in the Central and Indo-Pacific (Richmond 1988). Corals in these areas may therefore not respond favorably to deliberate breakage, leading to relatively high mortalities of transplants.

\section{Possible seasonal effects}

There were no discernible seasonal trends in growth of either controls or transplants of all species. Possible seasonal effects were apparent in the case of mortality, which peaked around July 1983.

The results so far indicate that the higher mortality rates may be related to longer day lengths and warmer temperatures. The possible detrimental effects of these factors on coral physiology and, by extension, on the ability of the organism to adapt and survive are discussed in Yap \& Gomez (1984). Similarly, Coles et al. (1976) observed that near-lethal temperatures occurred in the late summer (August-September) at Enewetak.

That the warm months may be associated with stress is also suggested by observations of extensive bleaching of Acropora hyacinthus and Pocillopora damicornis transplants in June 1983, 1 mo after transplantation. Controls of $P$. damicornis also had paler colors at this time, though apparently only the exposed parts were affected, since the shaded undersides retained the characteristic brown tint.

Jokiel \& Coles (1977) observed a similar reaction in Pocillopora damicornis in Hawaii. Bleaching was presumably caused by intense insolation, particularly since depths involved were relatively shallow. Hudson (1981) attributed the observed bleaching of Montastrea annularis transplants at inshore sites in Florida to the expulsion of zooxanthellae supposedly triggered by solar-heated water. Zooxanthellae expulsion, brought about by disruption of the coral-algal symbiotic association, is believed to be one of the first obvious symptoms of thermal stress (Jokiel \& Coles 1977, 1990).

In this study, normal coloration started to reappear some time in August, which was also when temperatures started to drop with the onset of the rainy season. Other authors (Shinn 1966, Coles 1975, Jaap 1979), too, have observed restoration of pigmentation some time after the occurrence of ambient temperature maxima.

Neither controls nor transplants of Pavona frondifera exhibited any bleaching at all during the entire duration of the study.

Towards the cooler season, transplants showed signs of becoming established. In December 1983, transplants of Acropora hyacinthus and Pocillopora damicornis were darkly pigmented, and polyps were fully expanded. In addition, instead of dying off at their border as was observed during the warm months, a number of $A$. hyacinthus transplants were actively calcifying in these parts, as indicated by thickened, white zones of new skeleton. We continued to observe this phenomenon in succeeding months. A. hyacinthus controls, too, exhibited pronounced zones of calcification along the periphery of live portions of colonies, a sign 
of recovery from previous tissue loss. By February 1984, a few $A$. hyacinthus transplants were observed to have calcified onto the rock to which they were attached with epoxy, and in March the same was observed for Pavona frondifera transplants.

Inspection of Fig. 4 reveals that mortality for both controls and transplants was somewhat elevated in 1983 as compared to 1984 . It should be noted that 1983 was an El Nin̄o year (Brown \& Suharsono 1990). Observations of corals in the Java Sea roughly parallel those of the present study (Brown \& Suharsono 1990). In that locality, bleaching apparently commenced in April 1983, resulting in 80 to $90 \%$ mortality, especially of branching species of Acropora and Pocillopora. Mortality ceased by the end of July, also about the time when corals in the present study were observed to recover from the effects of thermal stress.

\section{CONCLUSIONS}

The 3 species studied, Acropora hyacinthus, Pocillopora damicornis, and Pavona frondifera, are characterized by significantly different growth and survival strategies. A. hyacinthus has a naturally rapid growth rate, but also a high mortality rate, especially when broken up into smaller portions for transplantation. $P$. frondifera displayed the best survival and growth rates, both as undisturbed colonies and as transplants. Pocillopora damicornis may be considered intermediate between the two, having relatively high mortality rates, but adapting and growing well within a period of time after transplantation. These observations are reflections of the life strategies of the species, which evidently differ from one another, and which may be representative of an $r-K$ spectrum, with $A$. hyacinthus on one end $(r)$ and Pavona frondifera on the other $(K)$.

The above information should be useful in the context of coral transplantation for the purpose of habitat restoration on a relatively large scale. Knowledge of growth and survival strategies would aid in the selection of species suitable for transplantation. High survival rates are essential, and rapid growth rates a desirable characteristic, for transplantation efforts to succeed in establishing viable coral populations. The practical applications of such endeavors, however, and especially the costs involved, still need to be investigated.

Acknowledgements. The authors acknowledge the valuable assistance of Viva Banzon-Böhm, Dulce Rodriguez-Castelo and Jojo Morales. Ed Aro and Louie Tupas assisted in some of the field work. Al Licuanan, Marl Mamaril-Villanoy and Rommi Dizon were helpful in the data analysis. Financial support was provided by the Philippine Council for Agriculture and Resources Research and Development. This is contribution no. 198 of the Marine Science Institute.

\section{LITERATURE CITED}

Alino, P. M. (1985). Notes on the coral community structure of a backreef area in Cangaluyan Is., Pangasinan. Nat. appl. Sci. Bull. 37: 225-234

Anonymous (1984). Field assessment of survey methods. In Comparing coral reef survey methods. UNESCO Rep, mar Sci. 21: 109-160

Birkeland, C. (1976). An experimental method of studying corals during early stages of growth. Micronesica 12 $319-322$

Brown, B. E., Suharsono (1990). Damage and recovery of coral reefs affected by El Niño related seawater warming in the Thousand Islands, Indonesia. Coral Reefs 8: 163-170

Buddemeier, R. W. Kinzie, R. A. III (1976). Coral growth. Oceanogr. mar. Biol. A. Rev. 14: 183-225

Coles, S. L. (1975). A comparison of effects of elevated temperature versus temperature fluctuations on reef corals at Kahe Point, Oahu. Pacif. Sci. 29: 15-18

Coles, S. L., Jokiel, P. L., Lewis, C. R. (1976). Thermal tolerance in tropical versus subtropical Pacific reef corals. Pacif. Sci. 30: 159-166

Connell, J. H. (1973). Population ecology of reef-building corals. In: Jones, O. A., Endean, R. (eds.) Biology and geology of coral reefs, Vol. II. Academic Press, New York, p. 205-245

Gomez, E. D., Alcala, A. C., Yap, H. T., Alcala, L. C., Aliño, P. M. (1985). Growth studies of commercially important scleractinians. Proc. 5th int. Coral Reef Congr. 6: 199-204

Harriott, V. J. (1985). Mortality rates of scleractinian corals before and during a mass bleaching event. Mar. Ecol. Prog. Ser, 21: 81-88

Harriott, V. J., Fisk, D. A. (1988). Coral transplantation as a reef management option. Proc. 6th int. Coral Reef Symp. 2: 375-379

Harrison, P. L., Babcock, R. C., Bull, G. D., Oliver, J. K., Wallace, C. C., Willis, B. L. (1984). Mass spawning in tropical reef corals. Science 223: 1186-1189

Hudson, J. H. (1981). Response of Montastrea annularis to environmental change in the Florida Keys. Proc. 4th int. Coral Reef Symp. 2: 233-240

Jaap, W. C. (1979). Observations on zooxanthellae expulsion at Middle Sambo Reef, Florida Keys. Bull. mar. Sci. 29: $414-422$

Jokiel, P. L., Coles, S. L. (1977). Effects of temperature on the mortality and growth of Hawaiian reef corals. Mar. Biol. 43: 201-208

Jokiel, P. L., Coles, S. L. (1990). Response of Hawailan and other Indo-Pacific reef corals to elevated temperature. Coral Reefs 8: 155-162

Jordan, W. R. III, Gilpin, M. E., Aber, J. D. (eds.) (1987). Restoration ecology: a synthetic approach to ecological research. University Press, Cambridge

Kinzie, R. A. III, Sarmiento, T (1986). Linear extension rate is independent of colony size in the coral Pocillopora damicornis. Coral Reefs 4: 177-181

Maragos, J. E. (1974). Coral transplantation: a method to create, preserve and manage coral reefs. Seagrant Advisory Report No. UNIHI-SEAGRANT-AR-74-03 CORMAR14. University of Hawaii Seagrant Program, Honolulu, $30 \mathrm{pp}$

Mayor, A. G. (1924). Growth-rate of Samoan corals. Carnegie Inst. Washington Publ. 340: 51-72 and 26 plates

Ravera, O. (ed.) (1989). Ecological assessment of environmental degradation, pollution and recovery. Elsevier, Amsterdam

Richmond, R. H. (1988). Competency and dispersal potential 
of planula larvae of a spawning versus a brooding coral Proc. 6th int. Coral Reef Symp. 2: 827-831.

Shinn, E. A. (1966). Coral growth-rate, an environmental indicator. J. Paleontol. 40: 233-240 and 1 plate

Sokal, R. R., Rohlf, F. J. (1981). Biometry, 2nd edn. W. H Freeman, San Francisco

Willis, B. L., Ayre, D. J. (1985). Asexual reproduction and genetic determination of growth form in the coral Pavona cactus: biochemical genetic and immunogenic evidence Oecologia 65: 516-525

Yap, H. T. (1981). Studies on the growth, regeneration and transplantation of Acropora pulchra (Brook) (Coelenterata: Anthozoa) at Santiago Island, Bolinao, Pangasinan. M.Sc. Thesis. Marine Sciences Center, University of the Philippines, Quezon City

Yap, H. T., Gomez, E. D. (1984). Growth of Acropora pulchra.

This article was presented by C. Birkeland, Mangilao, Guam
II. Responses of natural and transplanted colonies to temperature and day length. Mar. Biol. 81: 209-215

Yap, H. T., Gomez, E. D. (1985). Growth of Acropora pulchra. III. Preliminary observations on the effects of transplantation and sediment on the growth and survival of transplants. Mar Biol. 87: 203-209

Yap, H. T., Licuanan, W. Y., Gomez, E. D. (1990). Studies on coral reef recovery and coral transplantation in the northern Philippines: aspects relevant to management and conservation. In: Yap, H. T (ed.) Proc. 1st ASEAMS Symp. Southeast Asian Marine Science and Environmental Protection. UNEP Regional Seas Reports and Studies 116 United Nations Environment Programme, Nairobi, p $117-127$

Zar, J. H. (1984). Biostatistical analysis, 2nd edn. PrenticeHall, N-J

Manuscript first received: September 17, 1991

Revised version accepted: April 2, 1992 